\title{
XXXV. On the anomaly-ruler; an instrument to assist in the graphic representation of the place of a gravitating projectile in an elliptic orbit
}

\author{
William John Macquorn Rankine C.E. F.R.S.E. F.R.S.S.A. \&c.
}

To cite this article: William John Macquorn Rankine C.E. F.R.S.E. F.R.S.S.A. \&c. (1850) XXXV.

On the anomaly-ruler; an instrument to assist in the graphic representation of the place of a gravitating projectile in an elliptic orbit , Philosophical Magazine Series 3, 37:250, 291-292, DOI: $10.1080 / 14786445008646602$

To link to this article: http://dx.doi.org/10.1080/14786445008646602

Published online: 30 Apr 2009.

Submit your article to this journal

Џ Article views: 2

View related articles $\sqsubset$ 
best with the more simple formula $\mathrm{Fe}^{2} \mathrm{Cy}^{5} \mathrm{NO}, 2 \mathrm{Na}+4 \mathrm{HO}$. The other elements, viz. the iron, the hydrogen and the nitrogen, when calculated according to both formulæ, so nearly coincide, that the difference cannot be ascertained with certainty by analysis. The amount of carbon appears to me decisive; because, as calculated according to both formulæ, it exhibits the greatest difference, and the quantity of carbon found is decidedly in favour of the more simple formula.

XXXV. On the Anomaly-Ruler; an Instrument to assist in the graphic representation of the place of a Gravitating Projectile in an Elliptic Orbit. By Wrumam John MacQUORN RANKINE, C.E., F.R.S.E., F.R.S.S.A. \&c.*

TT may sometimes be desirable, in lecturing on or in dis1 cussing the motions of comets, to possess the means of easily and rapidly laying down on a diagram, with as much accuracy as the scale of the drawing will permit, the places of such bodies in their elliptic orbits at given instants of time. The instrument which I shall now describe is intended to facilitate this operation.

It is simply a thin flat ruler, the form of which is represented by the shaded figure in the drawing, and which may be made of any convenient size.

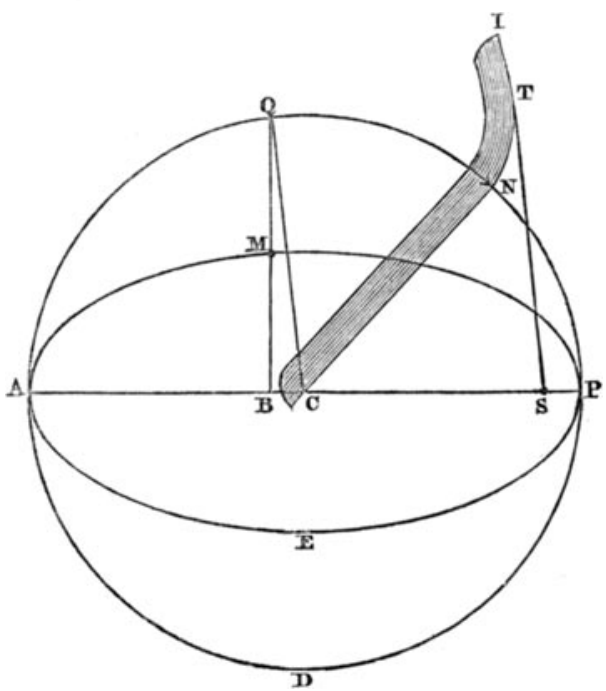

The fiducial edge, from $\mathrm{C}$ to $\mathrm{N}$, is straight. Those two points ought to be marked by fine transverse lines on both faces of the ruler. From $N$ to $I$ the fiducial edge has the 
292 Rev. T. P. Kirkman on Bisignal Univalent Imaginaries.

form of the involute of the circle whose radius is $\mathrm{CN}$, and centre C. The length of the curved portion of the ruler should be somewhat more than one-half of that of the straight part.

The use of this instrument is as follows:-

Problem.-The elliptic orbit of a body, gravitating towards a given focus, being given, to represent on a diagram the place of the body corresponding to a given mean anomaly.

Solution.-About a centre $\mathbf{C}$ with the radius $\mathrm{CN}$ describe the circle PNQADP, and let its diameter AP be taken to represent the major axis of the given elliptic orbit. Let $S$ represent the focus of attraction, $P$ the perihelion, and the angle $\mathrm{PCN}$ the given mean anomaly. Apply the anomalyruler to the diagram as shown in the drawing, so that the mark $\mathrm{C}$ shall be over the centre of the circle, the mark $\mathrm{N}$ at the end of the arc of mean anomaly, and the convexity of the involute NI towards the perihelion. From the focus S draw a straight line ST touching the involute NI. Through the centre $C$ draw a straight line $C Q$ parallel to $S T$ and on the same side of AP. From the point $Q$, where $C Q$ cuts the circle, draw a straight line $\mathrm{QB}$ perpendicular to $\mathrm{AP}$; divide this line by the point $\mathrm{M}$ in such a proportion that $\mathrm{BQ}: \mathrm{BM}:$ : major axis : minor axis of the elliptic orbit. Then the point $M$ represents the place of the body corresponding to the mean anomaly PCN. Q. E. I.

The proof of this solution follows immediately from the 31 st proposition of the first book of Newton's Principia.

If the entire ellipse PMAEP, similar to the given orbit, can be described with sufficient accuracy, the point $M$ may be determined by the intersection of the ordinate $B Q$ with the ellipse, without performing the proportional division of that line.

It has been suggested by the Astronomer Royal for Scotland, that by means of a turning-lathe a series of ellipses might be engraved on a plate with the same major axis, varying in excentricity between a circle and a straight line; and that impressions of this plate might be used in the graphic representation of cometic motions, with the aid of an anomaly-ruler of suitable size.

Glasgow, August 1850.

XXXVI. On Bisignal Univalent Imaginaries. By the Rev. Thomas P. Krrkman, M.A.*

TF abcdefghiklmnop be fifteen imaginaries having no linear relation to each other, and such that

$$
a^{2}=b^{2}=\ldots=p^{2}=-1,
$$

and also that by definition every pair of them, as $m$ and $n$,

* Communicated by the Author. 